\title{
Flutter analysis of a hybrid plate-like fiber-reinforced composite wing
}

\begin{abstract}
The aeroelastic flutter of a laminated hybrid composite wing was investigated. The composite wing was modelled as composite plates and the aeroelastic analysis has been carried out in the frequency-domain. Pre-determined fiber orientation of a 3-layers carbon/epoxy and glass/epoxy laminated plate has been employed with various aspect ratios. The modal approach and the Doublet-lattice Method (DLM) have been used herein to calculate the normal modes and the unsteady aerodynamics of the plate. The structural and aerodynamic models were connected using surface splines and the flutter speed has been calculated using the $\mathrm{p}-\mathrm{k}$ method that provides the eigenvalues at different air densities and airstream velocities. The study showed that it is imperative that the carbon/epoxy should be employed in the outermost layers in order to improve the flutter speed and flutter frequency.
\end{abstract}

Keyword: Aeroelasticity; Flutter; Hybrid; Laminated plate 